\title{
Absorptive capacity and post-acquisition inventor productivity
}

\author{
Katrin Hussinger
}

Published online: 2 October 2010

(C) The Author(s) 2010. This article is published with open access at Springerlink.com

\begin{abstract}
Inventors often experience a low productivity after their company has been subject to a merger or acquisition (M\&As). It is of central managerial interest to identify factors facilitating the integration of new inventive staff and thereby counteracting innovation declines after M\&As. This paper provides empirical evidence into the role of acquiring firms' absorptive capacity for the post-merger patent productivity of the acquired inventors. Based on a sample of 544 inventors employed by European acquisition targets in the period 2000-2001 it is shown that the post-merger productivity of acquired inventors is significantly higher within acquiring firms with a distinct absorptive capacity. It can be concluded that absorptive capacity is a firm capability that enhances the integration of inventors after firm takeovers.
\end{abstract}

Keywords M\&As $\cdot$ Absorptive capacity $\cdot$ Inventor productivity

JEL Classification $\mathrm{O} 30 \cdot \mathrm{O} 32 \cdot \mathrm{G} 34$

\section{Introduction}

In times of increasing technological competition the access to technological knowledge is one of the major objectives for mergers and acquisitions (M\&As) (Chakrabarti et al. 1994; Capron et al. 1998; Puranam et al. 2003; Graebner 2004). Technologically motivated firm acquisitions, however, often fail in the sense that post-merger innovation performance declines (e.g. Ravenscraft and Scherer 1987; Hitt et al. 1991, 1996). Strategists have

\footnotetext{
K. Hussinger $(\bowtie)$

Department of Organization and Strategy, University of Maastricht, Tongersestraat 53,

6211, LM, Maastricht, The Netherlands

e-mail: k.hussinger@maastrichtuniversity.nl

K. Hussinger

ZEW-Centre for European Economic Research, Mannheim, Germany

K. Hussinger

Catholic University Leuven, Leuven, Belgium
} 
argued that the main reason for decreases in post-merger innovation activities is a temporary shift of managerial attention towards the firm acquisition. Decision making on routine technological matters are delayed and managerial as well as financial efforts being supplied to day-to-day operations - even in the technological core of the company-are reduced (Pritchett 1985; Hall 1990a; Hitt et al. 1996; Veugelers 2006). The effect is amplified if post-merger integration suffers from insufficient ex-ante planning and inabilities to cope with differences in corporate culture (Larsson and Finkelstein 1999; Paruchuri et al. 2006). One implication is that the productivity of the acquired inventive labor force declines in the post-merger period (Ernst and Vitt 2000; Paruchuri et al. 2006; Kapoor and Lim 2007). A key managerial interest lies in identifying factors that foster integration of acquired inventors after firm takeovers and facilitate the exploitation of the new knowledge they introduce to the acquiring firm (Larsson and Finkelstein 1999; Ranft and Lord 2000; Puranam et al. 2003).

A low productivity of newly acquired inventors signals that there exist barriers to the exploitation of the acquired knowledge within the merged entity. This paper investigates the role of acquiring companies' absorptive capacity for post-merger patent productivity of acquired inventors. Absorptive capacity is defined as the firms' "ability to recognize the value of new, external knowledge, assimilate it and apply it to commercial ends" (Cohen and Levinthal 1990:128, 1989). This concept stipulates that firms do not benefit from externally acquired knowledge to the same extent and that the benefits derived from external knowledge are in part determined by the firms' own resources and capabilities. Absorptive capacity develops from the knowledge stocks within the firms (Cohen and Levinthal 1989; Zahra and George 2002) and the firms' links to external sources of knowledge (Cockburn and Henderson 1998). Absorptive capacity has been shown to increase firms' incentives to invest in research and development (R\&D) (Cohen and Levinthal, 1989). Further, firms with a distinct absorptive capacity have a superior ability to recognize upstream research (Cockburn and Henderson 1998) resulting in a better quality and timing of the outcome of their searches for external knowledge (Fabrizio 2009). Absorptive capacity, hence, leads to higher benefits from externally acquired knowledge (Arora and Gambardella 1994; Veugelers 1997; Gambardella 1992).

The superior capacity to recognize the value of new, external knowledge, assimilate it and apply it to commercial ends should be of advantage for acquiring firms in the immediate post-merger years. Absorptive capacity should help acquiring firms recognizing valuable, new ideas and practices introduced by the acquired inventors. Further, the implementation of new knowledge should be easier in firms with a distinct absorptive capacity since the required, flexible infrastructure for the adaption of new external ideas should be in place. The acquiring firms' ability to recognize and utilize the new inventors' knowledge should be visible in the acquired inventors' post-merger patent productivity.

This article empirically tests the effect of acquiring firms' absorptive capacity on postmerger patent productivity of the acquired inventive labor force. The analysis is based on a cross-industry sample of 544 inventors employed by European firms that were subject to a merger or acquisition in the years 2000 and 2001. Results from a sample selection model that accounts for possible departure of inventors after firm acquisition show that the postmerger productivity of acquired inventors is significantly higher within acquiring firms with a distinct absorptive capacity than within other firms.

The remainder of the paper is organized as follows: the next section reviews previous literature on post-merger inventor productivity. Section 3 describes the construction of the sample and Sect. 4 shows descriptive statistics. The empirical results are presented in Sect. 5 before the last section concludes. 


\section{Post-merger inventor productivity declines}

The often observed decline in innovation performance of firms after technologicallymotivated M\&As concerns an increasing number of academic scholars (Hitt et al. 1991, 1996; Chakrabarti et al. 1994; Capron et al. 1998; Ahuja and Katila 2001, Cassiman et al. 2005; Ornaghi 2009). While from an economic perspective a decline in post-merger innovation activities must not necessarily show an undesired acquisition outcome-as reduced innovation activities could also be the result of decreased innovation incentives due to an increase in market power after the acquisition-, several studies in the field of strategy and organization have shown that a lack of managerial attention towards innovation and insufficient post-merger integration cause innovation declines in the immediate post-merger years (Pritchett 1985; Hall 1990a; Hitt et al. 1996; Larsson and Finkelstein 1999; Paruchuri et al. 2006). The most important management insight from these studies is probably that insufficient ex-ante planning and the inability to cope with differences in corporate culture are key determinants of post-merger innovation declines at the firm level (Larsson and Finkelstein 1999; Ranft and Lord 2000; Puranam et al. 2003).

Lessons to be learned from firm-level studies about the causes of innovation declines after firm takeovers are, however, limited since post-merger integration strategies are typically firm-specific and, hence, quite heterogeneous. More detailed insights can be gained from case studies (e.g. Larsson and Finkelstein 1999; Cassiman et al. 2005) and studies that focus on a more narrowly defined unit of analysis than the firm, as, for instance, the department or the inventor. Against the background of a growing literature emphasizing the role of individuals and specialized human capital for knowledge creation (Zucker et al. 2002; Song et al. 2003; Felin and Hesterly 2007; Teece et al. 1997; Kogut and Zander 1992), in particular, the inventor level of analysis has received some attention recently in search for explanations for decreases in post-merger innovation performance (Ernst and Vitt 2000; Paruchuri et al. 2006; Kapoor and Lim 2007).

These studies enrich our understanding of post-merger innovation declines through several new insights. First of all, it has been shown that key inventors often leave after firm acquisitions (Ernst and Vitt 2000). In their pioneering study, Ernst and Vitt (2000), further, show that inventors that stay with the merged entity experience productivity declines in terms of the number of new patent applications and their quality. Cultural and organizational differences between the merging parties and a low level of technological proximity are identified as the main firm-level drivers of post-merger inventor departure and productivity declines (Ernst and Vitt 2000). Disruptive effects for the inventive working force after firm acquisitions are amplified if individuals loose status and centrality within the merged company and if the technological expertise of acquired inventors does not match the technological core competence of the acquiring firm (Paruchuri et al. 2006). Postmerger productivity decreases for acquired inventors are, however, temporary and a convergence towards the productivity level of inventors of the acquiring firm can be observed in the medium-term (Kapoor and Lim 2007). Factors facilitating productivity convergence are: a greater overlap in routines, a moderate overlap in skills and similarities between acquiring and acquired firm in terms of their organizational structure. In summary, inventor-level studies teach us that the acquired inventors' fit with the merged company is an important determinant of inventor productivity after firm takeovers and that inabilities to cope with differences in corporate and technology culture of the merging entities lead to productivity declines at the inventor level. This study contributes to the literature by focusing on absorptive capacity of the acquiring firm as an inherent firm-specific capability 
that presumably facilitates post-merger integration and, hence, limits post-merger productivity declines of the acquired inventive labor force.

Absorptive capacity as the firms' "ability to recognize the value of new, external knowledge, assimilate it and apply it to commercial ends" (Cohen and Levinthal 1990:128, 1989) has been shown to increase firms' ability to recognize valuable research, in the first place (Cockburn and Henderson 1998). Absorptive capacity, further, leads to higher benefits from externally acquired knowledge as it allows a more effective assimilation and exploitation (Arora and Gambardella 1994; Veugelers 1997; Gambardella 1992; Fabrizio 2009). Acquiring firms with a distinct absorptive capacity should, hence, be better able to recognize valuable new ideas and practices introduced by the acquired inventors. Further, the implementation of such new knowledge should be easier within firms with a significant absorptive capacity since they possess the required, flexible infrastructure for the adaption of new ideas. Acquiring firms' ability to recognize and utilize the new inventors' knowledge should be reflected in a higher post-merger patent productivity of the acquired inventors. This article empirically tests the hypothesis that acquiring firms' absorptive capacity supports post-merger productivity of the acquired inventive labor force.

\section{Construction of the sample}

The analysis is based on a newly created data set that contains information on firms that have been subject to an acquisition in Europe and their inventive labor force. The acquisition targets are taken from the merger and acquisition database of Bureau van Dijk Electronic Publishing, in which all European manufacturing firms that were subject to a majority acquisition in 2000 and 2001 were identified. Only targets that were acquired by European firms are selected. This yielded a sample of 9,913 acquisition targets. In order to identify technologically active firms the firm-level data was linked to firms' patent application records at the European Patent Office (EPO). In total, 919 of the acquisition targets applied for at least one patent at the EPO since its foundation in 1977.

Inventors employed by the acquisition targets were identified based on the inventor names (and addresses) on the target firms' patent application files. In order to trace inventors over time unique inventor identifiers had to be created for all inventors that were patenting for the acquisition targets at one point in time, in a first step. Information on patent applicants, application dates and technology classes of the patents was used in addition to inventor names and inventor addresses to support the accuracy. A few very common surnames that appeared with common first names (less than 5\% of the patent records) had to be excluded from the sample as those could not be unambiguously identified as one or more persons. Further, inventors with only one patent application were excluded from the inventor sample since they could not be traced over time based on their patent records. The resulting sample consisted of 653 uniquely identified inventors that applied for patents under the acquisition targets' names in the relevant period. Those inventors were active for 396 different acquisition targets. The relative small number of remaining inventors with more than one patent reflects the skewness of the patent productivity distribution.

In the next step, inventor mobility after the firm takeover was traced. In line with previous studies (Ernst and Vitt 2000; Palomeras 2004; Trajtenberg et al. 2006; Paruchuri et al. 2006; Hoisl 2007, 2009), inventor mobility was defined as a change of the patent applicant on the inventors' patents over time according to the EPO patent data. Three major problems arise if inventor mobility is identified in this way: 
(1) An inventor appears on a new firm's patent application but did not move: This can be the case for inventors moving to a subsidiary or joint ventures of the merged firm. Extensive manual checks of firm homepages and annual reports have been conducted to identify whether a new firm name on an inventor's patent application corresponds indeed to a new firm. As a result, the likelihood of falsely identified inventor moves should be negligible.

(2) An inventor moves and does not appear on patents after the M\&A again.

(3) An inventor does not move and does not appear on a patent after the M\&A again.

In order to avoid any bias due to (2) and (3) the empirical analysis focuses only on inventors that appear again on patent application files after their firm had been acquired. In total, 109 inventors were excluded from the inventor sample because they did not appear on patent documents after the firm acquisition anymore and, hence, could not be traced after the acquisition. Table 1 provides an overview on the construction of the sample.

Lastly, the acquiring firms were linked to their patent records at the EPO. The information on the acquiring firms' patenting activities are used to construct measures for their absorptive capacity.

\section{Definition of variables and descriptive statistics}

The final sample consists of 544 inventors involved in acquisition targets, 435 of which stayed with the merged company at least until 2005 after the takeover in 2000/2001. Table 2 shows some descriptive statistics for inventors that depart after acquisition and those that stay with the merged entity.

\subsection{Dependent variable}

The dependent variable is the acquired inventors' post-merger patent productivity, defined as the number of patents per inventor in the period 2002-2005. The distribution of the number of patents per inventor is skew. For the empirical analysis, the logarithm of the number of patents per inventor plus one is used. Robustness checks use the count of patents per inventor as a second dependent variable. Table 2 shows that inventors that left after

Table 1 Construction of the sample

\begin{tabular}{|c|c|c|c|}
\hline Step & Description & $\begin{array}{l}\text { Unit of } \\
\text { obs. }\end{array}$ & $\begin{array}{l}\# \text { of } \\
\text { obs. }\end{array}$ \\
\hline 1 & $\begin{array}{l}\text { Identification of European acquisition targets acquired by European firms } \\
\text { in } 2000 / 2001\end{array}$ & Firm & 9,913 \\
\hline 2 & Selection of acquisition targets with at least one patent application at the EPO & Firm & 919 \\
\hline 3 & $\begin{array}{l}\text { Identification of unique inventors within the } 919 \text { acquisition targets: } \\
\text { - Inventors with common names were dropped as it was not possible } \\
\text { to create a unique id for them } \\
\text { - Inventors with only one patent application were dropped as their mobility } \\
\text { cannot be traced }\end{array}$ & Inventor & 653 \\
\hline 4 & $\begin{array}{l}\text { Inventors that did not appear on patent applications after the takeover were } \\
\text { dropped as they could not be traced over time }\end{array}$ & Inventor & 544 \\
\hline
\end{tabular}


Table 2 Descriptive statistics

\begin{tabular}{|c|c|c|c|c|c|c|c|}
\hline & \multirow[t]{2}{*}{ Variables } & \multicolumn{2}{|l|}{ Leave } & \multicolumn{2}{|l|}{ Stay } & \multirow[b]{2}{*}{ Difference } & \multirow[b]{2}{*}{$\mathrm{SD}$} \\
\hline & & Mean & SD & Mean & SD & & \\
\hline \multirow{11}{*}{$\begin{array}{l}\text { Inventor } \\
\text { characteristics }\end{array}$} & Log(post-acquisition patents) & 1.15 & 0.57 & 1.35 & 0.67 & $-0.20 * * *$ & 0.08 \\
\hline & $\log$ (pre-acquisition patents) & 1.54 & 0.83 & 1.22 & 1.10 & $0.32 * * *$ & 0.12 \\
\hline & Time since last patent & 1.09 & 1.45 & 0.65 & 1.22 & $0.44 * * *$ & 0.15 \\
\hline & Private patent & 0.24 & 0.43 & 0.07 & 0.25 & $0.17 * * *$ & 0.03 \\
\hline & $\log$ (seniority) & 2.20 & 0.69 & 1.76 & 1.04 & $0.44 * * *$ & 0.11 \\
\hline & Pre-acquisition diversification & 0.45 & 0.31 & 0.32 & 0.30 & $0.13 * * *$ & 0.03 \\
\hline & $\log ($ pre-acquisition citation rate) & -2.00 & 0.67 & -2.07 & 0.64 & 0.07 & 0.08 \\
\hline & $\begin{array}{l}\text { Small group of inventors in target } \\
\text { firm }(<5)\end{array}$ & 0.28 & 0.45 & 0.32 & 0.47 & -0.04 & 0.05 \\
\hline & $\begin{array}{l}\text { Large group of inventors in target } \\
\text { firm }(>4)\end{array}$ & 0.15 & 0.36 & 0.28 & 0.45 & $-0.13 * * *$ & 0.05 \\
\hline & Inventor centrality for the target firm & 3.86 & 3.49 & 5.49 & 3.76 & $-1.63 * * *$ & 0.43 \\
\hline & $\begin{array}{l}\text { Inventor centrality for the acquiring } \\
\text { firm }\end{array}$ & 3.22 & 3.25 & 2.89 & 3.36 & 0.33 & 0.39 \\
\hline \multirow{6}{*}{$\begin{array}{l}\text { Acquirer } \\
\text { characteristics }\end{array}$} & Acquirer patent stock & 0.94 & 1.26 & 0.91 & 1.36 & 0.03 & 0.16 \\
\hline & $\begin{array}{l}\text { Log(acquirer citation stock/patent } \\
\text { stock) }\end{array}$ & -1.62 & 0.96 & -1.76 & 0.91 & 0.14 & 0.11 \\
\hline & $\begin{array}{l}\text { Reference stock to same IPC class/ } \\
\text { total reference stock }\end{array}$ & 0.02 & 0.05 & 0.02 & 0.05 & 0.00 & 0.01 \\
\hline & Acquirer diversification & 0.28 & 0.36 & 0.28 & 0.36 & 0.00 & 0.04 \\
\hline & Acquirer coauthor stock/patent stock & 0.89 & 1.02 & 0.82 & 1.07 & 0.07 & 0.12 \\
\hline & Acquirer NPR stock/reference stock & 0.12 & 0.32 & 0.16 & 0.41 & -0.03 & 0.05 \\
\hline \multirow{3}{*}{$\begin{array}{l}\text { Deal } \\
\text { characteristics }\end{array}$} & Acquired stake & 93.70 & 14.90 & 94.46 & 14.48 & -0.76 & 1.69 \\
\hline & Horizontal acquisition & 0.44 & 0.50 & 0.49 & 0.50 & -0.05 & 0.06 \\
\hline & Cross-border acquisition & 0.52 & 0.50 & 0.44 & 0.50 & 0.08 & 0.06 \\
\hline \multirow{8}{*}{$\begin{array}{l}\text { Inventor } \\
\text { technology } \\
\text { classes }\end{array}$} & Technology class 1 & 0.21 & 0.41 & 0.13 & 0.34 & $0.08 * *$ & 0.04 \\
\hline & Technology class 2 & 0.47 & 0.50 & 0.71 & 0.46 & $-0.24 * * *$ & 0.05 \\
\hline & Technology class 3 & 0.21 & 0.41 & 0.10 & 0.30 & $0.11 * * *$ & 0.04 \\
\hline & Technology class 4 & 0.04 & 0.21 & 0.03 & 0.16 & 0.01 & 0.02 \\
\hline & Technology class 5 & 0.04 & 0.21 & 0.04 & 0.19 & 0.00 & 0.02 \\
\hline & Technology class 6 & 0.47 & 0.50 & 0.59 & 0.49 & $-0.12 * *$ & 0.06 \\
\hline & Technology class 7 & 0.25 & 0.43 & 0.15 & 0.36 & $0.10 * *$ & 0.04 \\
\hline & Technology class 8 & 0.20 & 0.40 & 0.10 & 0.30 & $0.10 * * *$ & 0.04 \\
\hline \# Observations & & 89 & & 435 & & & \\
\hline
\end{tabular}

***,**,* Indicate statistical significance at the 1\%-, 5\%-, 10\%-level

firm acquisition are, on average, significantly less productive in the post-merger years than their colleagues that stayed with the merged entity.

\subsection{Measuring absorptive capacity}

Absorptive capacity is proxied by two variables that measure the acquiring firms' ability to recognize, assimilate and exploit external knowledge as visible from the usage of external knowledge sources in the past. 
The first measure is the stock of external coauthors defined as:

$$
\text { coauthor stock }_{t}=\text { coauthors }_{t}+(1-\delta) \text { coauthor stock }_{t-1} \text {. }
$$

$\delta$ depicts a depreciation rate of 15 percent, which is the commonly used depreciation rate for knowledge stocks (e.g. Hall 1990b). The stock of coauthors is divided by the patent stock of the firm to account for the correlation between both variables. The stock of the acquiring firms' coauthors captures the ability of these firms to acquire, produce and use external knowledge in collaboration with external inventors.

The second measure is the stock of non-patent references made in the acquiring firms' patents. Non-patent references (NPRs) reflect mainly citations to scientific articles (Callaert et al. 2004). Hence, the stock of NPRs reflects the ability of acquiring firms to exploit scientific knowledge. The usage of scientific knowledge requires a significant absorptive capacity (Cockburn and Henderson 1998; Fabrizio 2009) as it demands the ability to decode and utilize codified knowledge (von Hippel 1994). The stock of NPRs is defined in analogy to the stock of coauthors:

$$
N P R \text { stock }_{t}=N P R_{t}+(1-\delta) N P R_{t-1}
$$

Again, a depreciation rate of 15 percent is employed. The variable is normalized by the stock of the total number of references made by the firms' patent applications.

Regarding the two proxies for acquiring firms' absorptive capacity Table 2 displays no statistically significant differences in the unconditional means for inventors that stay with the merged entity and those that leave. This relationship will be further explored in a multivariate analysis.

\subsection{Control variables}

A range of control variables is used in order to control for characteristics of inventors, acquiring firms and heterogeneity of the firm acquisitions. On the inventor level, the most important control variable is the inventor's pre-acquisition patent productivity defined as the number of patents inventors filed before the acquisition took place. It is expected that productive inventors stay productive after the firm acquisition. Further, the time since the inventor's last patent application before the take-over is accounted for. If an inventor's last patent application occurred a long time ago she might be of less interest for an acquiring firm as her knowledge might be outdated. Inventor seniority is taken into account as the number of years since the inventor's first patent application at EPO. The more senior an inventor is the more likely she is to take management positions rather than a purely scientific job within a firm. Inventor excellence is measured by the logarithm of the citations the inventor's patents received within a five-year window after application over her total patents in the same period.

Moreover, the degree of technological diversification of the inventor's patent portfolio is taken into account. Technological diversification is calculated as follows based on the IPC (International Patent Classification) 3-digit technology classes $j$ :

$$
\text { diversity }_{i}=1-\sum_{j}\left(\frac{N_{i j}}{N_{i}}\right)^{2}
$$

$N$ refers to the number of pre-acquisition patents of inventor $i$ in technology class $j$. The measure is close to one for inventors with a diversified technology portfolio and equals zero for inventors that patent exclusively in one particular technology class. 
Following previous studies (Ernst and Vitt 2000; Paruchuri et al. 2006), the centrality of inventors for the acquiring firm is used as a control variable. In order to calculate this measure inventor $i$ 's technology portfolio $F_{i}$ is defined as the assemblage of her patent stocks for all 3-digit IPC technology classes. The technology portfolio of the acquiring firm $k$ is defined analogously. This yields two technology vectors, one for inventor $i, F_{i}$, and one for acquiring firm $k, F_{k}$. The patent stocks per technology field are formulated as percentages of the total patent stock of inventor and firm, respectively, in order to control for size differences of their patent portfolios of inventors and firms. Technological relatedness of the patent portfolios of inventor $i$ and firm $k, T_{i k}$, is calculated as:

$$
T_{i k}=\frac{F_{i} F_{k}}{\sqrt{\left(F_{i^{\prime}} F_{i}\right)\left(F_{k^{\prime}} F_{k}\right)}} ; \quad 0 \leq T_{i k} \leq 1
$$

The higher the value this measure takes, the higher the importance of the specific inventors for the acquiring firm. In analogy, the centrality of the inventor regarding the target firm's technology portfolio is calculated. Inventors that are central for the technology development within the acquired firm are expected to be more attractive for the acquiring firm. Both centrality measures are multiplied by 100 .

In order to control for inventor independence a binary variable is defined indicating whether an inventor owns private patents. Inventors that applied in the past for patents under their own name without any firm involvement are presumably less dependent from their employers and their labs than others. Moreover, it is taken into account whether the inventor worked in a target firm that employed more than one patenting inventor. Two binary variables are defined. The first one indicates whether the inventor worked in a firm with more than four inventors. The second one indicates whether the inventor worked in a firm with four or less inventors, but more than one inventor. A final inventor characteristic taken into account is the field of technological activity. Eight binary variables take the value one if the inventor has applied for at least one patent in the corresponding first-digit IPC class in the past (see Table 3 for a description of the technology field dummies).

Next to the inventor characteristics some characteristics of the acquiring firm are taken into account. The acquiring firm's innovation capabilities are proxied by its patent stock, defined as:

$$
{\text { patent } \text { stock }_{t}=\text { patents }_{t}+(1-\delta) \text { patent stock }}_{t-1}
$$

$\delta$ depicts the depreciation rate of knowledge and is set to 15 percent. Further, the citations received by the acquiring firm's patents within a five-years window after patent application

Table 3 Technology class dummies

\begin{tabular}{lll}
\hline Technology class dummy & First-digit IPC class & Technology field \\
\hline 1 & A & Human necessities \\
2 & B & Performing operations; transportations \\
3 & C & Chemistry; metallurgy \\
4 & D & Textiles; paper \\
5 & E & Fixed constructions \\
6 & F & Mechanical engineering; lighting; \\
7 & & heating; weapons, blasting \\
8 & G & Physics \\
\hline
\end{tabular}


are used as a measure for the acquiring firm's innovation quality. The measure is normalized by the firm's patent stock. The logarithm of the variable is used to account for the skewness of this variable's distribution. Next, the technological diversity of the acquiring firms' patent portfolio is calculated analogously to the diversification index of the inventors (see above). Moreover, the number of references made to patents within the same technology field is taken into account. Firms that refer to a few different technology fields only have a stronger technology focus and might only be interested in very special inventor profiles. Again, this variable is divided by the acquiring firm's total reference stock to account for the high correlation between these two variables.

Besides inventor's and acquiring firm's characteristics heterogeneity of the acquisitions is accounted for by using a measure for the acquired stake, a binary variable that takes the value one if the deal was horizontal, i.e. whether the merging firms were affiliated with the same 3-digit NACE sector, and a binary variable indicating whether the M\&A was crossborder within Europe.

The descriptive statistics presented in Table 2 show that the main differences between inventors that depart from and stay with the merged firm appear on the inventor level. There are no significant differences regarding the acquiring firms' characteristics and the characteristics of the acquisition itself.

\section{Empirical model and results}

\subsection{Empirical model}

This section undertakes an empirical analysis of the determinants of inventors' post-merger patent productivity. The variables of key interest are the two proxies for the absorptive capacity of the acquiring firm. In this context, it is essential to control for sample selection as not all inventors stay with the merged firm after their employer had been acquired. In a recent paper, Siegel and Simons (2010) argue that takeovers are a welcome opportunity for acquiring firms to improve the match between employer and employee in order to improve long-term firm performance. In consequence, employees that fit best are kept in the merged firms while those that are considered a bad fit are dismissed.

For this reason, a Heckman selection model (Heckman 1974, 1976, 1979) ${ }^{1}$ is applied that takes into account that inventors that stay with the merged firm are a selective group. The Heckman selection model estimates the likelihood of inventors to leave the firm after the acquisition in a first step and then controls for inventor selectivity in the second step estimation for the productivity of the subsample of acquired inventors that stay with the merged firm:

$$
\begin{aligned}
& \operatorname{stay}_{i}^{*}=Z_{i}^{\prime} \alpha+u_{i} \\
& \operatorname{stay}_{i}=\left\{\begin{array}{lll}
1 & \text { if } & \text { stay }_{i}^{*}>0 \\
0 & \text { if } & \text { stay }_{i}^{*} \leq 0
\end{array}\right. \\
& \text { patent productivity }_{i}=\left\{\begin{array}{lll}
X_{i}^{\prime} \beta_{1}+e_{i} & \text { if } & \text { stay }_{i}^{*}>0 \\
0 & \text { if } \quad \text { sta }_{i}^{*} \leq 0
\end{array}\right.
\end{aligned}
$$

A probit model is estimated for the probability that the inventor stays with the merged entity, in the first step. Post-merger inventor departure is modeled as a function of the

\footnotetext{
$\overline{1}$ The Heckman selection model is also known as Tobit Type II model (Amemiya 1985).
} 
inventor's pre-merger performance and the further control variables on the inventor, the acquisition and the firm level, $Z$.

In the second step, an ordinary least squares (OLS) model is estimated to investigate the effect of the acquiring firm's absorptive capacity on the post-merger patent productivity for the subsample of acquired inventors that stayed with the merged firm. A set of control variables accounts for inventor, acquiring firm and acquisition characteristics, $X$. In addition, the patent productivity equation contains a selection correction term $\gamma$, which accounts for the fact that inventor departure after firm acquisition does not occur randomly but depends on a number of observable and unobservable factors (as becomes visible from estimating Eq. 1). Under the assumption of joint normality of the error terms in both equations the selection correction term can be proxied by the mills ratio, $\gamma=\phi\left(Z_{i}{ }^{\prime} \alpha\right) /$ $\Phi\left(Z_{i}^{\prime} \alpha\right)$, where $Z_{i}^{\prime} \alpha$ is the linear prediction of the first-step probit model for inventor mobility:

$$
\text { patent productivity }{ }_{i}=X_{i}^{\prime} \beta_{1}+\gamma\left(\widehat{Z_{i}^{\prime} \alpha}\right) \beta_{2}+e_{i}
$$

The patent productivity Eq. $2^{\prime}$ can be estimated by OLS with the mills ratio as an additional regressor controlling for sample selection.

Although the Heckman selection model is in theory identified by the nonlinear shape of the selection correction term, in practice, exclusion restrictions are often required to ensure that the model is identified. The exclusion restriction should determine inventor mobility but not her post-merger productivity. Given the present data set it is difficult to define such a variable. The exclusion restriction used here is the centrality of the inventor with regard to the acquired firm. In order to improve identification the second, third of fourth polynomial of the variable are used as additional regressors in the selection equation. Although the centrality variable is not a perfect exclusion restriction from a theoretical point of view since it is not clear why there should be no effect on inventor post-merger productivity it is statistically valid: while centrality impacts post-merger inventor departure there is no impact on post-merger productivity (as $X^{2}$-show, see Table 4). As an additional validity test of the estimated model Fig. 1 shows that the predicted mills ratio has a nonlinear shape, as required by theory, converging to zero for the inventors with the highest likelihood of staying with the merged entity.

\subsection{Estimation results}

\subsubsection{Who stays after an acquisition?}

Table 4 presents the estimation results. The first column shows the determinants of the likelihood to stay with the merged company after acquisition (Eq. 1). The most relevant predictor is the inventors' pre-acquisition patent productivity. The effect of pre-merger inventor patent productivity on the likelihood to stay with the merged entity appears to be nonlinear. The likelihood of inventor departure increases in productivity possibly due to the receipt of more attractive outside job offers for the most productive scientists (Hoisl 2007, 2009; Palomeras 2004). In the context of M\&As, however, the acquiring firm might have better insights into the skills and capabilities of a key inventor and might, hence, be willing to outbid other firms in terms of job offers for the top inventors that fit best to the acquiring company's profile (Siegel and Simons 2010). In response, inventors with an intermediate productivity turn out to be most likely to move as compared to the "stars" and the least productive inventors. 


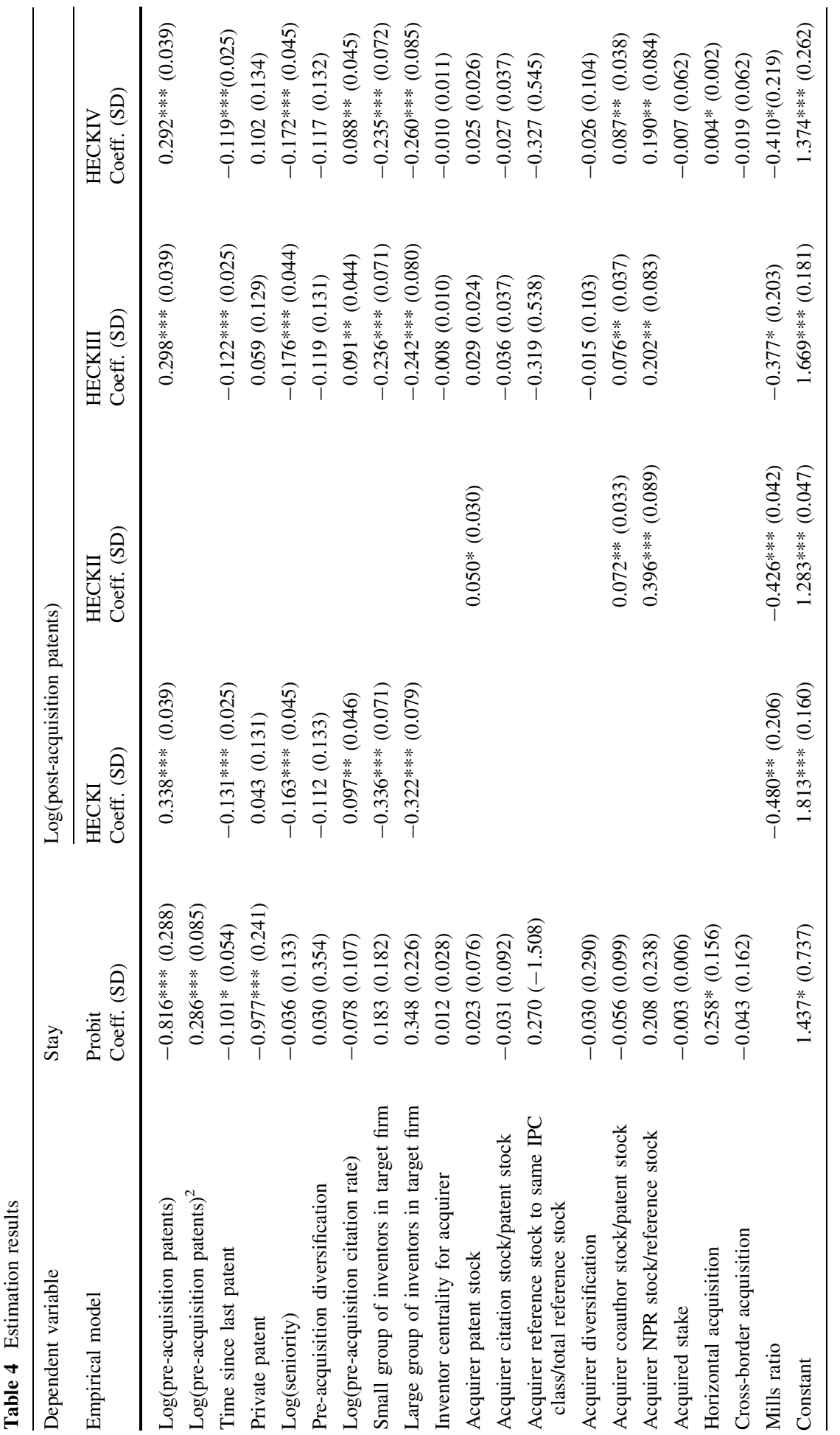




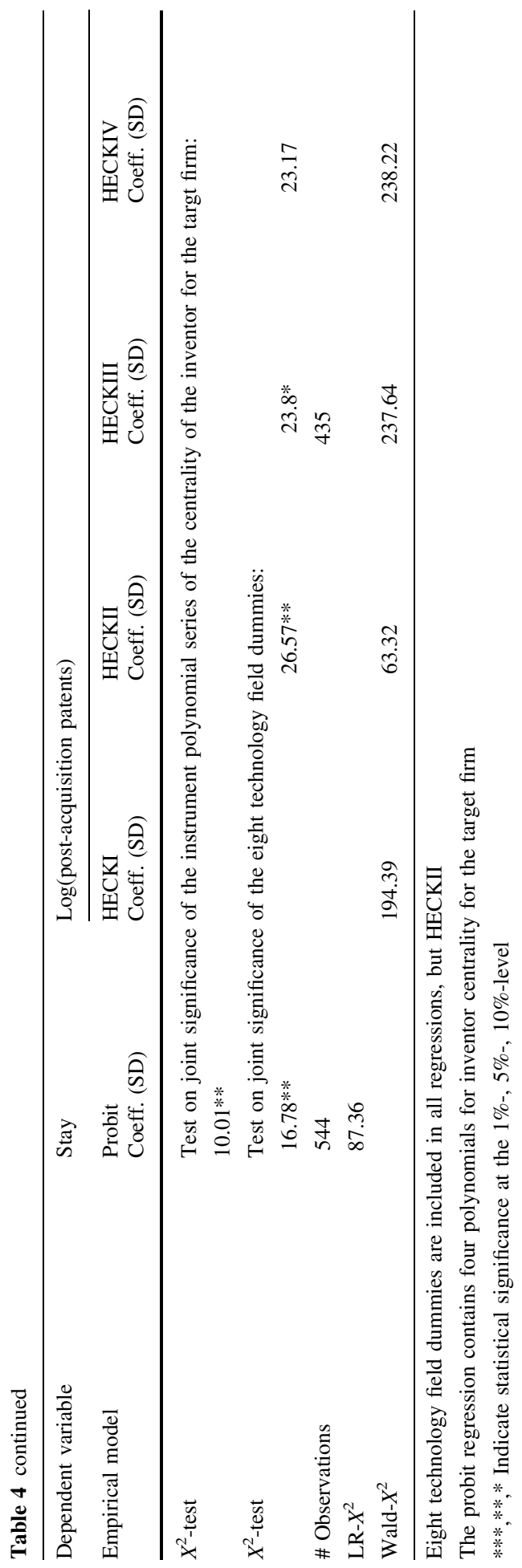




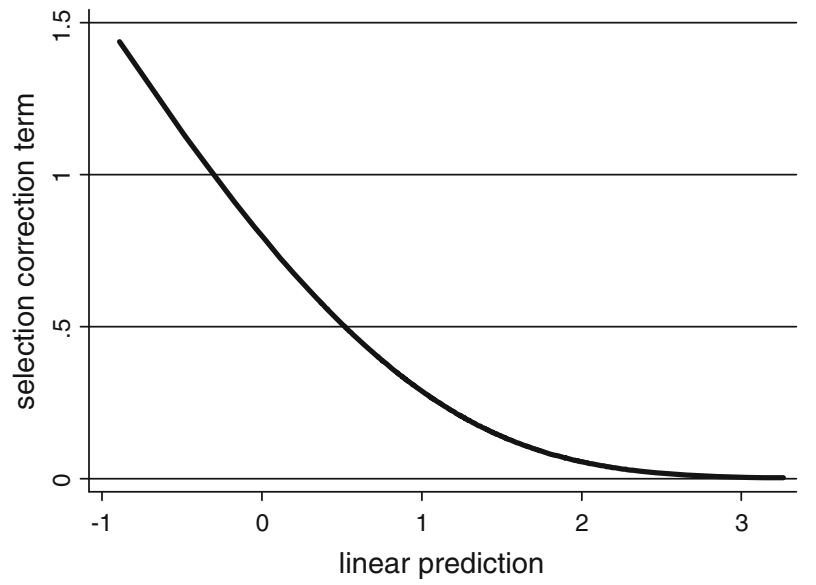

Fig. 1 Estimated selection correction term

Furthermore, the estimation results show that inventors with private patents, i.e. those that are able to work independently, are more likely to leave after an acquisition. Inventors that filed their last patent a long time before the acquisition took place are also more likely to leave. Post-merger inventor mobility depends significantly on the technology field the inventor is active in as a $X^{2}$-test on the joint significance of the technology field dummies indicates.

Moreover, inventors are less likely to depart if acquired and acquiring firm are active in the same industry. Lastly, the polynomial series of the inventor's centrality for the acquired firm, i.e. the exclusion restriction, is significant as a $X^{2}$-test on joint significance at the bottom of Table 4 shows. The remaining variables have no predictive power for the likelihood of an inventor to leave after a M\&A. Hence, there is also no evidence that the acquiring firm's absorptive capacity measured as its past exposure to external knowledge, in terms of external coauthors on patents and NPRs, impacts the likelihood of post-merger departure.

\subsubsection{Post-merger inventor productivity and absorptive capacity}

The remaining four columns of Table 4 show the results for inventor post-merger patent productivity within the merged firm (Eq. $2^{\prime}$ ). Four different specifications are presented to show robustness of the results with regard to the model specification. The first model (HECKI) only takes inventor characteristics into account; the second specification (HECKII) includes only the acquiring firm's patent stock and the measures for absorptive capacity as regressors. Model HECKIII combines inventor and firm characteristics, while model HECKIV uses the full set of available control variables, including the characteristics of the acquisition itself.

Regarding the variables of key interest, the results show a positive effect of absorptive capacity on inventor productivity. A large coauthor network and many links to the nonpatent literature by the acquiring firm increase the post-merger patent productivity of the acquired inventive labor force. This finding supports the hypothesis that absorptive capacity allows acquiring firms to better recognize, assimilate and exploit the knowledge and ideas introduced by the acquired inventors so that their immediate post-merger patent productivity is higher than inventor productivity in acquiring firms with less experience with external knowledge acquisition. 
With regard to the control variables, inventor characteristics, again, play a key role: the more productive an inventor was before the acquisition took place the more productive she is in the merged firm. Patent productivity is higher the more citations the inventor's previous patents received signaling that the inventor's work is important for future technology development. Inventor seniority as measured by the time since the inventor's first patent filing at the EPO turns out to have a negative effect on post-merger productivity. Seniority may be associated with a higher inflexibility of the inventor hampering her integration into a new working environment. Furthermore, the likelihood to take on positions with management tasks rather than pure research positions increases with seniority. This would also be reflected in a lower patent productivity of senior inventors. The negative effects of the binary variables indicating whether the inventor worked in a small or larger group of inventors before the acquisition took place suggests that inventors that used to work in teams have more difficulties to integrate themselves into a new working environment as well. Finally, the selection correction term (mills ratio) is statistically significant indicating that the estimation results would be biased if selectivity of the inventors would not have been taken into account.

\subsubsection{Robustness checks}

To show robustness of the findings presented in Table 4, some additional regression results are presented in Table 5. The first three columns show estimation results for standard OLS regressions where selectivity of inventors is not taken into account, i.e. Eq. $2^{\prime}$ is estimated without the selection correction term. Further, count data models are estimated with the number of post-acquisition patents (rather than the log of the number of post-acquisition patents) as dependent variable. Three different specifications are presented in Table 5. The results are very similar to the ones presented in Table 4, both in sign and magnitude of the estimated coefficients. Most important, the variables capturing the absorptive capacity of the acquiring firm are positive and statistically significant.

\section{Discussion}

Prior research observed that the productivity of inventors acquired through a merger or acquisition often declines in the immediate post-merger years (Ernst and Vitt 2000; Paruchuri et al. 2006; Kapoor and Lim 2007). A low productivity of the acquired inventive labor force signals barriers to the exploitation of the knowledge they introduce to the acquired firm. These barriers are partly caused by ex-ante insufficiently planned postmerger integration and the inability of inventors and acquiring firms to cope with differences in corporate culture (Larsson and Finkelstein 1999; Ranft and Lord 2000; Puranam et al. 2003). Hence, it is of central managerial interest to identify factors that facilitate postmerger integration of acquired inventors in order to enhance the integration and exploitation of the skills and knowledge they offer to the acquiring firm.

This paper investigates the role of the acquiring firms' absorptive capacity for postmerger inventor patent productivity. A high immediate post-merger patent productivity proxies successful integration and utilization of the ideas and the knowledge of the acquired inventors within the acquiring firm. Results for a sample of 544 inventors employed by European acquisition targets in the period 2000-2001 show that the postmerger productivity of acquired inventors is higher within firms with a distinct absorptive capacity than within other firms. Defined as the firms' ability to recognize, assimilate and 


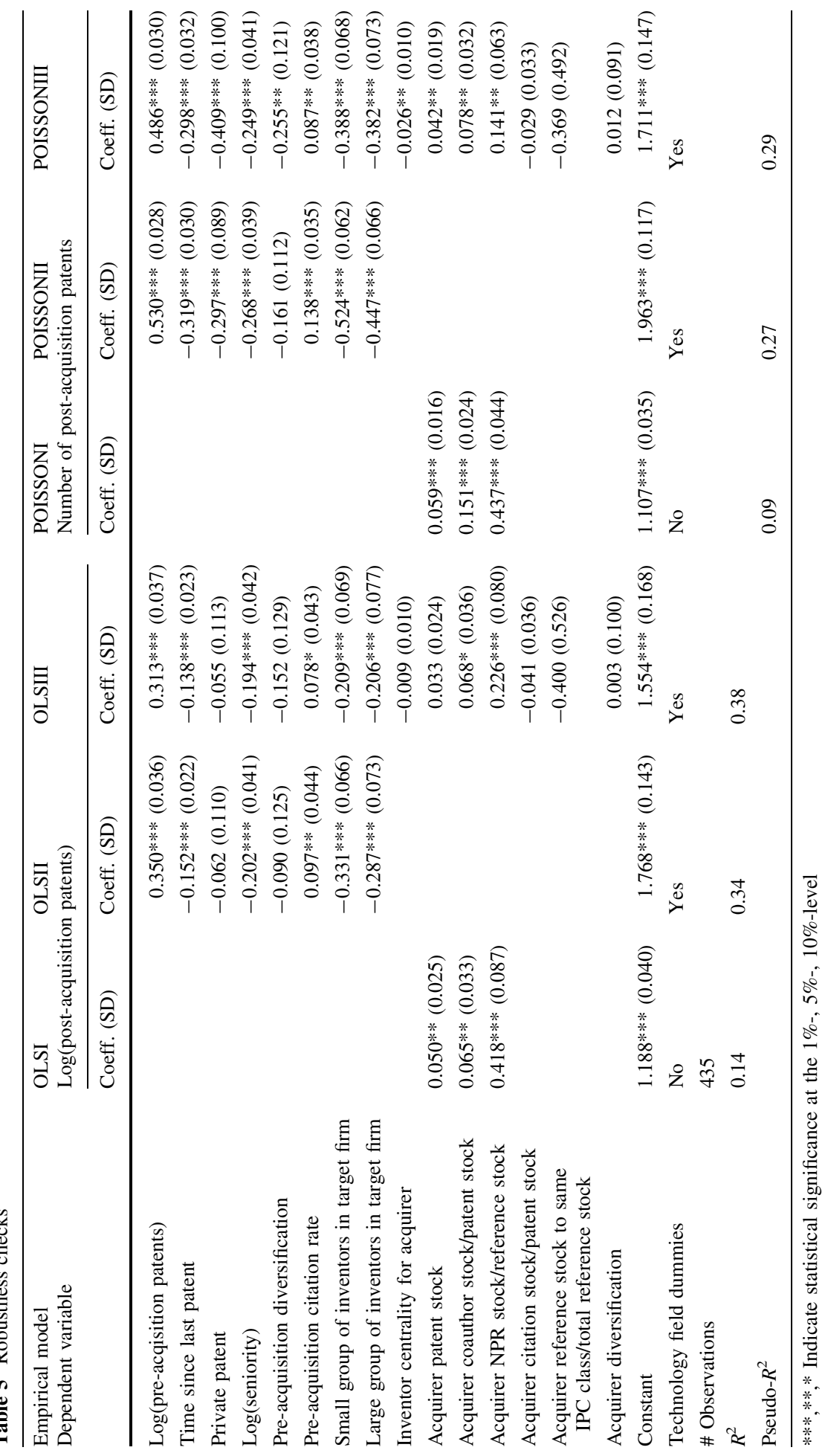


exploit external knowledge, absorptive capacity, hence, supports the acquiring firms' ability to identify new ideas and valuable knowledge introduced by the acquired inventors and their exploitation.

Previous studies have identified inventor characteristics and the quality of the match between inventors and acquiring companies in technology and organization space as the main determinants for successful integration of acquired inventors into the merged entity (Ernst and Vitt 2000; Paruchuri et al. 2006; Kapoor and Lim 2007). The general conclusion of these studies is that a sound and early planning of the post-merger integration process would be desirable for the acquiring firm in order to be able to identify key inventors and to determine the appropriate tasks and positions for them in the merged firm. Special communication and incentives schemes should be set up to facilitate integration of acquired inventors (Paruchuri et al. 2006). The results of this study show that acquiring firms with a distinct absorptive capacity have to take fewer means than others for achieving the same productivity level of the acquired inventors in the immediate post-merger years. In firms with significant absorptive capacity effective communication and integration schemes to integrate externally developed knowledge and new ideas have evolved over time, facilitating the recognition, integration and exploitation of valuable external ideas and knowledge.

A limitation of this study, as of any large-scale merger study, is the lack of detailed information on the acquisition motive and the post-merger integration schemes within the individual firms. Hence, this study can be seen as a supplement to case study evidence investigating the means taken by individual firms in order to integrate acquired inventors after firm acquisitions in more detail. Furthermore, it would be desirable to have more information on the individual inventors as for instance whether the firm acquisition implies a loss in status or salary for the inventor (Paruchuri et al. 2006).

Open Access This article is distributed under the terms of the Creative Commons Attribution Noncommercial License which permits any noncommercial use, distribution, and reproduction in any medium, provided the original author(s) and source are credited.

\section{References}

Ahuja, G., \& Katila, R. (2001). Technological acquisitions and the innovation performance of acquiring firms: A longitudinal study. Strategic Management Journal, 22(3), 197-220.

Amemiya, T. (1985). Advanced econometrics. Cambrisge: Havard University Press.

Arora, A., \& Gambardella, A. (1994). Evaluating technological information and using it. Journal of Economic Behavior \& Organization, 24, 91-114.

Callaert, J., Van Looy, B., Verbeek, A., Debackere, K., \& Thijs, B. (2004). Traces of prior art: An analysis of non-patent references found in patent documents. Scientometrics, 69(18), 3-20.

Capron, L., Dussauge, P., \& Mitchell, W. (1998). Resource redeployment following horizontal mergers and acquisitions in Europe and the United States 1988-1992. Strategic Management Journal, 19, 631-661.

Cassiman, B., Colombo, M., Garrone, P., \& Veugelers, R. (2005). The impact of M\&A on the R\&D process. An empirical analysis of the role of technological and market relatedness. Research Policy, 34(2), 195-220.

Chakrabarti, A. K., Hauschildt, J., \& Süverkrüp, C. (1994). Does it pay to acquire technological firms? $R \& D$ Management, 24(1), 47-56.

Cockburn, I., \& Henderson, R. (1998). Absorptive capacity, coauthoring behavior and the organization of research in drug discovery. Journal of Industrial Economics, 46(2), 157-182.

Cohen, W. M., \& Levinthal, D. A. (1989). Innovation and learning: Two faces of R\&D. Economic Journal, 99, 569-596.

Cohen, W. M., \& Levinthal, D. A. (1990). Absorptive capacity: A new perspective on learning and innovation. Administrative Science Quarterly, 35, 128-152. 
Ernst, H., \& Vitt, J. (2000). The influence of corporate acquisitions on the behavior of key inventors. $R \& D$ Management, 30(2), 105-119.

Fabrizio, K. (2009). Absorptive capacity and the search for innovation. Research Policy, 38(2), $255-267$.

Felin, T., \& Hesterly, W. S. (2007). The knowledge-based view, nested heterogeneity, and new value creation: Philosophical considerations on the locus of knowledge. Academy of Management Review, 32(1), 195-218.

Gambardella, A. (1992). Competitive advantages from in-house scientific research: The US pharmaceutical industry in the 1980s. Research Policy, 21, 391-407.

Graebner, M. (2004). Momentum and serendipity: How acquired leaders create value in the integration of technology firms. Strategic Management Journal, 25, 751-777.

Hall, B. H. (1990a). The impact of corporate restructuring on industrial research and development. Brookings Papers on Economic Activity, 1990(1), 85-136.

Hall, B. H. (1990b). The manufacturing sector master file: 1959-1987. Cambridge, MA: NBER Working Paper.

Heckman, J. J. (1974). Shadow prices, market wages and labor supply. Econometrica, 42(4), 679-694.

Heckman, J. J. (1976). The common structure of statistical models of truncation, sample selection and limited dependent variables and a simple estimator for such models. Annals of Economic and Social Measurement, 5(4), 475-492.

Heckman, J. J. (1979). Sample selection bias as a specification error. Econometrica, 4(7), 153-162.

Hitt, M. A., Hoskisson, R. E., Ireland, R. D., \& Harrison, J. S. (1991). Effects of acquisitions on R\&D inputs and outputs. Academy of Management Journal, 34(3), 693-706.

Hitt, M. A., Hoskisson, R. E., Johnson, R. A., \& Moesel, D. D. (1996). The market for corporate control and firm innovation. Academy of Management Journal, 39(5), 1084-1119.

Hoisl, K. (2007). Tracing mobile inventors - the causality between inventor mobility and inventor productivity. Reserach Policy, 36(8), 1107-1127.

Hoisl, K. (2009). Does mobility increase the productivity of inventors? Journal of Technology Transfer, 34, 212-225.

Kapoor, R., \& Lim, K. (2007). The impact of acquisitions on the productivity of inventors at semiconductor firms: A synthesis of knowledge-based and incentive-based perspectives. Academy of Management Journal, 50(5), 1133-1155.

Kogut, B., \& Zander, U. (1992). Knowledge of the firm, combinative capabilities, and the replications of technology. Organization Science, 3(3), 383-397.

Larsson, R., \& Finkelstein, S. (1999). Integrating strategic, organizational, and human resource perspectives on mergers and acquisitions: A case survey of synergy realization. Organization Science, 10(1), 1-26.

Ornaghi, C. (2009). Mergers and innovation in big pharma. International Journal of Industrial Organization, 27, 70-79.

Palomeras, N. (2004). Markets for inventors: Examining mobility patterns of engineers in the semiconductor industry. Barcelona, Spain: Mimeo. Universitat Pompeu Fabra.

Paruchuri, S., Nerkar, A., \& Hambrick, D. C. (2006). Acquisition integration and productivity losses in the technical core: Disruption of inventors in acquired companies. Organization Science, 17(5), 545-562.

Pritchett, P. (1985). After the merger: Managing the shockwaves. New York: Dow Jones, Irwin.

Puranam, P., Singh, H., \& Zollo, M. (2003). A bird in the hand or two in the bush? Integration trade-offs in technology-grafting acquisitions. European Management Journal, 21(2), 179-184.

Ranft, A. L., \& Lord, M. D. (2000). Acquiring new knowledge: The role of retaining human capital in acquisitions of high-tech firms. Journal of High Technology Management Research, 11(2), 295-319.

Ravenscraft, D. J., \& Scherer, F. M. (1987). Life after takeover. Journal of Industrial Economics, 36, 147-157.

Siegel, D., \& Simons, K. L. (2010). Assessing the effects of mergers and acquisitions on firm performance, plant productivity, and workers: New evidence from matched employer-employee data. Strategic Management Journal, 31, 903-916.

Song, J., Almeida, P., \& Wu, G. (2003). Learning-by-hiring: When is mobility more likely to facilitate interfirm knowledge transfer? Management Science, 49(4), 351-365.

Teece, D. J., Pisano, G. P., \& Shuen, A. (1997). Dynamic capabilities and strategic management. Strategic Management Journal, 18, 509-534.

Trajtenberg, M., Shiff, G., Melamed, R. (2006). The names game: Harnessing inventors' patent data for economic research. NBER Working Paper 12479.

Veugelers, R. (1997). Internal R\&D expenditure and external technology sourcing. Research Policy, 26, 303-316.

Veugelers, R. (2006). Literature review on M\&A and R\&D. Cassiman, B., \& Colombo, M.G. (eds.). Merger and acquisitions-the innovation impact. 
Von Hippel, E. (1994). "Sticky information" and the locus of problem solving: Implications for innovation. Management Science, 40(4), 429-439.

Zahra, S. A., \& George, G. (2002). Absorptive capacity: A review, reconceptualization and extension. Academy of Management Review, 27(2), 185-203.

Zucker, L. G., Darby, M. R., \& Armstrong, J. S. (2002). Commercialization knowledge: Capture, and firm performance in biotechnology. Management Science, 48(1), 138-153. 